\title{
Improving time use and self-efficacy increases task performance: validation of a novel process
}

\section{Harrison Garcia}

\author{
Corresponding Author: Northeastern University, Boston, MA, USA
}

ORCID ID: 0000-0002-1970-6332

Email: garcia.ha@northeastern.edu

\begin{abstract}
College students are expected to develop time management skills to minimize procrastination and best perform in the tasks they face during education, but many do not implement time management practices and nearly all have trouble focusing on and completing assignments. Contemporary work and theory suggest that time management does not have an effect on task performance, but it can improve selfefficacy, which does correlate with task performance. A time management tool that also worked to improve self-efficacy was thus used to see if increasing self-efficacy could decrease time spent on tasks, i.e., task performance. Analysis of data collected from time and mood tracking before and after intervention demonstrated a significant decrease in time spent working $(p<0.001)$ and significant increases in actual and in perceived productivity $(p=0.039$ and $p=0.009$ respectively). The results suggest that implementing practices to improve time management and self-efficacy may increase task performance, but further research must be done to control for specific factors that may confound this effect.
\end{abstract}

Key words: Organizational behavior, time management, productivity, task performance

\section{Introduction}

Students, including myself, tend to lack time management skills and procrastinate until the last minute. It is known that use of technology and procrastination is strongly correlated, and even way back in 2002, research found that $72 \%$ of college students checked their email at least once a day (Jones, 2008, Erdoğan et al., 2013). Flash forward to 2017 , post release and widespread use of smartphones, $94 \%$ of college students report using their phones in class for "academic purposes," being if the student used their phones in class to "assist with their learning" as decided by themselves or by their instructor (Marans, 2017). While more than $75 \%$ of these students report that their phones help them learn, it has been noted as early as 1998 that college students are vulnerable to internet addiction (Marans, 2017, Kandell, 1998). Surveys on cell phone use and mental health in college students demonstrated a positive correlation between electronic usage and feelings of anxiety (Lepp et al., 2014). This work shows that college students, generally, use their phones too much and aren't great at getting things done, both of which heighten anxiety. The problems are clear, but what can be done about it?

Time management, a goal-setting process of organizing and allocating one's time to different activities, is a commonly thought of solution to decrease procrastination. Numerous studies show that people, especially those in academia and high-level professions, are able to self-regulate their use of time when given the right tools (Kim et al., 2019, Talebi et al., 2019, Oettingen et al., 2015, Kwan and Tin, 2014). College students who practice effective time management have reported decreased levels of anxiety (Misra and McKean, 2000). Other research has shown that effective time management has a strong inverse correlation with stress and a strong positive correlation with grade point average (Macan et al., 1990, Britton and Tesser, 1991). While time management may come off as an effective solution to the problems college students have due to its implementation of Bandura's goal setting theory, it is clear in organizational behavior and in psychology that although time management is related to task satisfaction, it is not related to task performance, i.e., productivity (Macan, 1994, Bandura et al., 1999). If effective time management does not directly affect the 
outcome of a student's task, being maximizing grades while maintaining work life balance, then why does good time management improve productivity, mental health, and academic performance?

Self-efficacy, which is one's perceived ability to successfully complete a task, is known in organizational behavior to correlate with increased task performance; research has found that effective time management can increase self-efficacy, which may increase grades (Locke et al., 1984, Stajkovic, 1997, Bandura et al., 1999, Klassen et al., 2008, Terry, 2002). Engendering high self-esteem and self-efficacy through positive reinforcement and time management techniques have also shown to increase task performance in students; in addition, students with high self-efficacy have shown to procrastinate much less than students low selfefficacy (Wehmeyer et al., 1998, Zhijie, 2005, Haycock et al., 1998, Klassen et al., 2008). While time management may not directly increase task performance, it certainly seems to decrease stress/anxiety and can promote self-efficacy, which, in turn, may decrease procrastination and increase task performance. No time management tools to date have emphasized development of both time management skills and selfefficacy, prompting the need to create and test a tool for time management that includes them.

\section{Methodology}

Microsoft Excel (365) was used to create a time tracking sheet due to its adaptability, cloud capability, and ease of use. Each 24-hour day was broken into 96 increments of 15 minutes. In the best case, time was tracked by the participant ( $\mathrm{H}$. Garcia) in real time, but if that was not possible, the participant was asked to go through their call, text, email history, and calendars to try to recall what they did during the day. The participant inputted letters to indicate time spent on activities in the following categories: sleep, prep, eat, lecture, work, productive, music/chill, social, shop, travel, phone, chores, pray, TV, internet, and miscellaneous (S1 Figure). These categories were then to be grouped into 3, broader categories of self-care, work, and leisure, adapted from known patterns of everyday activity (Vagni and Cornwell, 2018). The participant used the Meddis scale answer questions about their mood and perceived productivity, which act as surrogates for self-efficacy, before they went to bed (Meddis, 1972). Questions were based on the Brief Mood Introspection Scale (BMIS) (Mayer and Gaschke, 1988).

Time tracking was broken into two parts of one week's length: the initial part had the participant track their time and mood without any interventions, while the second part introduced interventions to increase their self-efficacy and to assist in their time management. Intervention materials included daily reminders, sent via email using Microsoft Outlook's delayed send feature, to improve the participant's self-efficacy (S1 Table). Monday.com was used to assist the participant with time management techniques and task planning. To best assist with this, the participant used only Monday.com to track their tasks, and the participant inputted the due date, task priority, task status, and estimated time to completion for each task. The participant worked on only one task at a time as multitasking has been suggested to decrease productivity (Rosen, 2008).

The TI-84 Calculator were used for statistical analysis. Every whole hour was considered as an individual point in each sample. Data from each time category was summed from before and after intervention and hours were rounded up to the whole to be analyzed using 2 proportion $z$ tests. BMIS data were converted to numbers from the Meddis scale, reverse scored, and pleasant-unpleasant scores were calculated from data before and after intervention. Two sample $t$ tests were used to compare mood and perceived productivity data before and after intervention, while chi squared goodness of fit tests were used to compare time use across the 3 categories of leisure, self-care, and work. An average 8 hours of sleep and a 09:00-17:00, 8hour workday would leave 8 hours of leisure in a day; this 1/3-time distribution was used as the null hypothesis and as the expected values for the chi squared tests. Significance levels were not set due to small sample size and because of the tendency to $p$-hack in the field of psychology.

\section{Results}

3,456 increments of 15-minutes were tracked over 36 days, totaling 672 and 192 hours before and after intervention respectively. Total time usage before and after intervention (Figure 1) was found to be significantly different $(p<0.001)$. Categorized time before the intervention was not found to be different from the null $1 / 3$ distribution $(p=0.434)$. Time spent on work significantly decreased $(p<0.001)$, while time spent on self-care $(p=0.08)$ and on leisure $(p=0.005)$ increased (Table 1). BMIS pleasant-unpleasant scores, 
calculated from 6 days of mood tracking before and after intervention, increased from a mean of 38.5 before intervention to a mean of 41.5 after intervention $(p=0.199)$, indicating that mood became more positive after intervention. Perceived productivity increased from a mean score of 1.67 before intervention to a mean of 3.17 after intervention $(p=0.009)$. Actual productivity, being the proportion of days that the participant completed all self-assigned tasks, significantly increased from a proportion of $2 / 6$ productive days to $5 / 6$ productive days after intervention $(p=0.039)$. Reported Meddis score on stress before sleep, serving as a surrogate for stress levels, did not change significantly before and after intervention $(p=0.367)$. All data followed normal distributions according to $Q Q$ and bar plotting.

Table 1: Percentages of time spent on activities before and after intervention

\begin{tabular}{|c|c|c|c|}
\hline & BEFORE & AFTER & P-VALUE \\
\hline SELF-CARE & 0.356770833 & 0.411458333 & 0.08 \\
\hline WORK & 0.3203125 & 0.165364583 & 1.69E-05 \\
\hline LEISURE & 0.322916667 & 0.423177083 & 0.005 \\
\hline
\end{tabular}

The proportions were obtained by dividing the number of hours, before and after intervention, in each category by the total number of hours tracked ( 672 before and 192 hours after intervention). Time use by category before and after intervention was then compared using 2 proportion $\mathrm{z}$ tests.

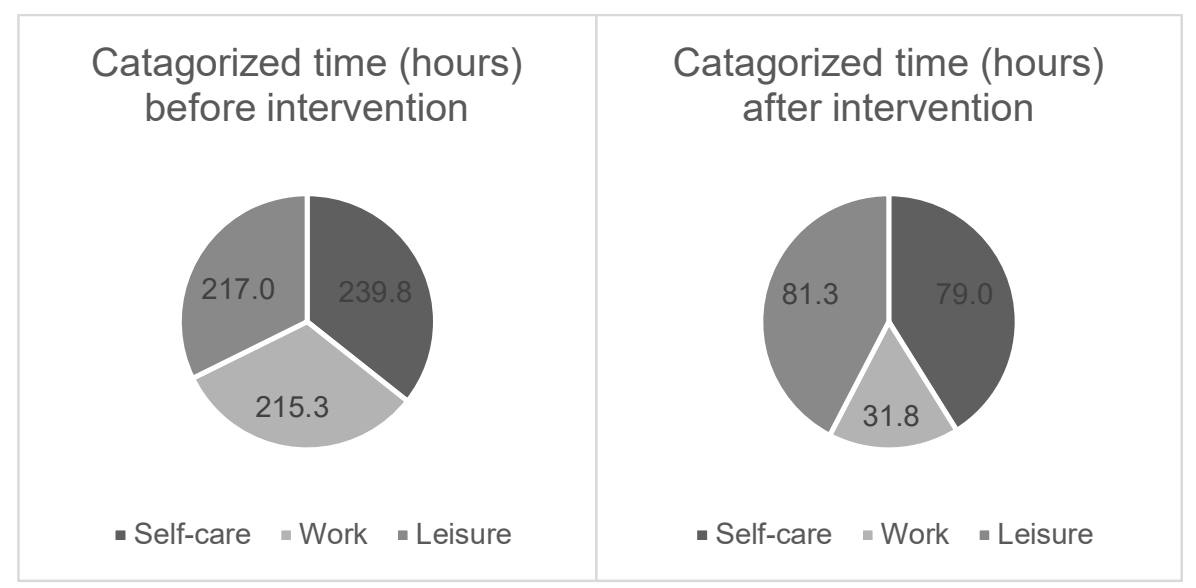

Fig. 1: Pie charts of categorized time usage before and after intervention

Time tracked by the participant was converted from 15-minute increments into whole hours and grouped into the 3 categories of work, self-care, and leisure; sleep, preparation for the day, and eating were summed into self-care, time spent in lecture, work, on general productive tasks, travel, chores, praying, and miscellaneous usage were summed into work, and time spent on music/chill, social, shopping, phone, TV, and internet were summed into the leisure category.

\section{Discussion}

This is currently the only study conducted on the intersection between time management, self-efficacy, mood, and task performance. Questions pertaining to mood and to perceived productivity served as surrogates for self-efficacy, while time tracking data and responses to questions regarding the completion of tasks served as surrogates for task performance. Less time was spent on work while productivity and positive mood increased after intervention; therefore, it can be inferred that the intervention increased self-efficacy and task performance. The participant also reported no change in the amount of work assigned, demonstrating that the decreased time spent on work was attributed to better time management practices rather than having less tasks to complete.

At first, converted Meddis scores for mood were summed and compared using 2-proportion z-tests. It was then realized that each point in the score were not individual objects of the sample, so scores for all emotions 
for each day were summed and the averages of the scores before and after intervention were compared using 2 sample $t$ tests. While positive mood, self-efficacy, and productivity did increase after intervention, a large sample size is needed to best confirm this finding.

While the original objective was to have two weeks of time and mood tracked between control and intervention, only the week before and the week of intervention were used in statistical analysis as the participant sometimes forgot to survey their mood. Although this decreased sample size, most results turned out to be significant. The participant also experienced more than a few 24 to 48 -hour gaps in time tracking, so time use was recalled using tactics described in the methods section, but this introduced a significant source of error. A future study should send reminders to participants at the end of the day to complete time tracking and to survey their mood/productivity. Another limitation is that there were no controls to determine if the improvements in productivity and in self-efficacy were caused by the self-efficacy intervention or by the time management intervention. It is recommended that a future study employ crossover study design using 4 groups: one control, one with only the self-efficacy improvement intervention, one with only the time management intervention, and one with both the time management and self-efficacy improvement intervention. The results from this study should not be interpreted as definitive due to the small sample sizes of 6 days and because each hour was considered a point in the sample for categorized time comparisons. The results do, however, justify further research on the subject.

The largest issue while conducting this was the advent of the novel coronavirus. It can be seen in the data that normal study, sleep, and work patterns became more sporadic and spread out due to difficulty focusing when working from home. Average bedtime shifted from 23:30 to 03:00, while time spent working jobs plummeted from more than $16 \%$ of time used to around $1 \%$ of time used. This extreme decrease can be attributed to the fact that the participant left their part time job in Boston, and that a large part of time spent working on co-op tasks in the office was spent on their phone or surfing the web. Much more time was spent sleeping and on socializing with/taking care of family because of the quarantine. Still, more tasks were completed every day and less time was spent on them, demonstrating better time management and task efficiency.

\section{Conclusions}

This research demonstrated that time management and self-efficacy improvement may improve mood and productivity, warranting the need for a larger trial to confirm the effects of these results on task performance. More work must be done for the sake of statistical significance and efforts should be made to control for confounding factors.

\section{References}

BANDURA, A., FREEMAN, W. \& LIGHTSEY, R. 1999. Self-efficacy: The exercise of control. Springer.

BRITTON, B. K. \& TESSER, A. 1991. Effects of time-management practices on college grades. Journal of educational psychology, 83, 405.

ERDOĞAN, U., PAMUK, M., EREN-YÜRÜK, S. \& PAMUK, K. Academic procrastination and mobile phone. International Academic Conference on Education, Teaching and E-learning, 2013.

HAYCOCK, L. A., MCCARTHY, P. \& SKAY, C. L. 1998. Procrastination in college students: The role of selfefficacy and anxiety. Journal of counseling \& development, 76, 317-324.

JONES, S. 2008. Internet goes to college: How students are living in the future with today's technology, Diane Publishing.

KANDELL, J. J. 1998. Internet addiction on campus: The vulnerability of college students. Cyberpsychology \& behavior, 1, 11-17.

KIM, B., LEE, S., HONG, H. \& HAN, K. 2019. Automated Time Manager: Effectiveness of Self-Regulation on Time Management Through a Smartphone Application. IEEE Access, 7, 90891-90903. 
KLASSEN, R. M., KRAWCHUK, L. L. \& RAJANI, S. 2008. Academic procrastination of undergraduates: Low self-efficacy to self-regulate predicts higher levels of procrastination. Contemporary Educational Psychology, 33, 915-931.

KWAN, A. S. \& TIN, H. M. University students' self-regulation of time management. 2014. Conference under title.

LEPP, A., BARKLEY, J. E. \& KARPINSKI, A. C. 2014. The relationship between cell phone use, academic performance, anxiety, and Satisfaction with Life in college students. Computers in Human Behavior, 31, 343-350.

LOCKE, E. A., FREDERICK, E., LEE, C. \& BOBKO, P. 1984. Effect of self-efficacy, goals, and task strategies on task performance. Journal of applied psychology, 69, 241.

MACAN, T. H. 1994. Time management: Test of a process model. Journal of applied psychology, 79, 381.

MACAN, T. H., SHAHANI, C., DIPBOYE, R. L. \& PHILLIPS, A. P. 1990. College students' time management: Correlations with academic performance and stress. Journal of educational psychology, 82, 760.

MARANS, J. 2017. Cellphones in School are Essential to Learning, Say Students [Online]. Top Hat. Available: https://tophat.com/blog/cellphones-in-school-student-survey/ [Accessed].

MAYER, J. D. \& GASCHKE, Y. N. 1988. The experience and meta-experience of mood. Journal of personality and social psychology, 55, 102.

MEDDIS, R. 1972. Bipolar factors in mood adjective checklists. British Journal of Social and Clinical Psychology, 11, 178-184.

MISRA, R. \& MCKEAN, M. 2000. College students' academic stress and its relation to their anxiety, time management, and leisure satisfaction. American journal of Health studies, 16, 41.

OETTINGEN, G., KAPPES, H., GUTTENBERG, K. \& GOLLWITZER, P. 2015. Self-regulation of time management: Mental contrasting with implementation intentions. European Journal of Social Psychology, 45.

ROSEN, C. 2008. The myth of multitasking. The New Atlantis, 105-110.

STAJKOVIC, A. D. 1997. Self-efficacy and task performance: A meta-analysis.

TALEBI, M., AHMADI, F. \& KAZEMNEJAD, A. 2019. Dynamic self-regulation as an effective time management strategy for clinical nurses: A qualitative study. Collegian, 26, 463-469.

TERRY, K. P. S. 2002. The effects of online time management practices on self-regulated learning and academic self-efficacy. University Libraries, Virginia Polytechnic Institute and State University.

VAGNI, G. \& CORNWELL, B. 2018. Patterns of everyday activities across social contexts. Proceedings of the National Academy of Sciences, 115, 6183-6188.

WEHMEYER, M. L., AGRAN, M. \& HUGHES, C. 1998. Teaching self-determination to students with disabilities: Basic skills for successful transition, ERIC.

ZHIJIE, Z. 2005. Time Management Disposition, Self-esteem, Self-efficacy and Learning Satisfaction: An Analysis of the Mediation Model. PSYCHOLOGICAL SCIENCE-SHANGHAI-, 28, 566. 


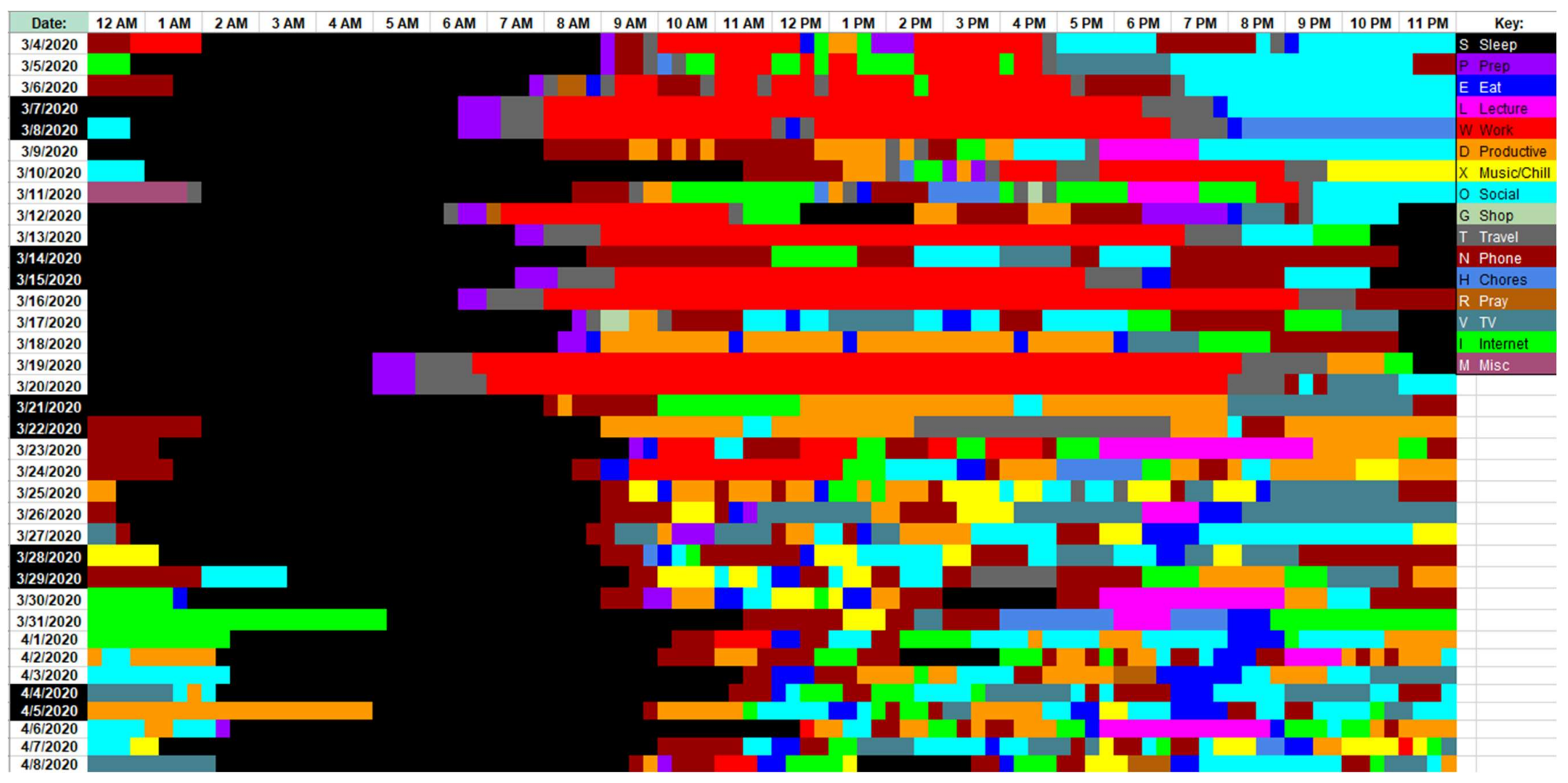

Supplemental Fig. 1: Time use over 36 days, divided into 15-minute chunks

The participant tracked their activities in real time or recalled time use to their best knowledge, using call/text history, emails, and calendar events as aids. The participant moved out of their dorm on Sunday, 3/22/2020, and began the intervention on 4/1/2020. The participant began working from home after moving out. They also ordered a ukulele to their home before leaving Boston, so the "Music/chill" category was added on 3/24/2020 and previous events were edited to reflect the changes. 
DATE

$4 / 1 / 2020$

$4 / 2 / 2020$

$4 / 3 / 2020$

$4 / 4 / 2020$

$4 / 5 / 2020$

$4 / 6 / 2020$

$4 / 7 / 2020$

$4 / 8 / 2020$

$4 / 9 / 2020$

\section{MESSAGE}

Be kind to yourself! Listen to the voice in your head that says you're doing great because you are! A good way to do this is to talk to yourself the way you talk to others. You are just as amazing and can do just as amazing as everyone around you!

Productivity does not define who you are. Especially during these crazy times, we should not base our value off of what we do. None of us are really working from home, we're at home struggling to work. If you can't do everything, communicate that to yourself and to those you're doing work for. They'll understand because they're going through the same things.

Take frequent brakes! Productivity falls off the roof when you spend too much time on one task, and research shows that you get do better work and remember more when focusing on many little tasks rather than doing one task.

You're not lazy! Don't ask the universe for the ability to succeed, you already have it right inside of you! If you need to do something, drink a cup of coffee, turn off your phone, and get it done! Procrastination is a choice that can easily be ignored.

Everybody makes mistakes. If you forget something, get it done and apologize when you have the deliverable. It's hard to manage everything when you have so much to do.

Focus on what you can change! It's easy to get hung up on all the things that are out of your control, but it won't achieve much. Instead, try to focus your energy on identifying the things that are within your control and seeing what you can do about them.

Celebrate small victories! Sent those emails? Awesome! Now watch the next episode of the series you are binging and get onto the next task. Rome wasn't built in a day; dividing your large tasks into baby steps and acknowledging them with a reward is the best way to get things done.

Apologize and forgive. Whether it be forgiving yourself on your own defeat or limitations or letting go of grudges, embracing and recognizing is the best way to let go.

Weed your garden. If you can't help yourself, who will be there for you? No matter what, you are ALWAYS of first priority. And if someone guilts you, remember: you don't owe anyone anything.

Supplemental Table 1: Daily messages sent to participant via email to improve self-efficacy

Messages were automatically sent to the participant via email from a Microsoft Outlook (365) client every morning at 09:00. Message content was based on references and on author's own knowledge. 